\title{
Low pertussis antibody levels in maternal and umbilical cord blood samples in Turkey
}

\author{
Ebru Türkoğlu ${ }^{1}$, Cemile Sönmez ${ }^{2}$, Esra Özer ${ }^{3}$, Nilay Çöplü ${ }^{4}$, Zafer Kurugöl ${ }^{5}$ \\ ${ }^{1}$ Department of Neonatology, Tepecik Training and Research Hospital, Izmir, ${ }^{2}$ Microbiology Reference Laboratories, Public \\ Health Institution of Turkey, Ankara, ${ }^{3}$ Department of Pediatrics, Sıtkı Koçman University, Faculty of Medicine, Muğla, \\ ${ }^{4}$ Microbiology Department, Diskapt Yildirim Beyazit Training and Research Hospital, Ankara, ${ }^{5}$ Department of Pediatrics, \\ Ege University Medical Faculty, Bornova, Izmir, Turkey.
}

E-mail: zafer.kurugol@ege.edu.tr

Received: 9th November 2016, Accepted: 8th January 2017

SUMMARY: Türkoğlu E, Sönmez C, Özer E, Çöplü N, Kurugöl Z. Low pertussis antibody levels in maternal and umbilical cord blood samples in Turkey. Turk J Pediatr 2016; 58: 573-578.

Pertussis continues to cause significant mortality and morbidity in many countries despite high vaccine coverage, especially among young infants. The aim of the study was to determine pertussis antibody levels in paired maternal and cord blood samples, to evaluate the placental transfer of these antibodies, and to assess whether newborn infants have adequate antibody levels against pertussis. Antibody titers to pertussis toxin (anti-PT) and filamentous hemagglutinin (anti-FHA) were measured by in-house enzyme linked immunosorbent assay (ELISA) in 251 paired maternal delivery and cord blood samples. Geometric mean concentrations (GMCs) of pertussis antibodies and cord:maternal GMC ratios were calculated. GMCs of maternal anti-PT and anti-FHA antibodies at delivery were 4.12 and $9.89 \mathrm{EU} / \mathrm{ml}$, respectively. Cord GMCs were $133 \%$ and $131 \%$ of maternal delivery values for PT and FHA, respectively; demonstrating effective placental transfer. However, cord pertussis antibodies were at a low concentration; $5.49 \mathrm{EU} / \mathrm{ml}$ for PT and $12.73 \mathrm{EU} / \mathrm{ml}$ for FHA. Only $34.6 \%$ of infants had protective anti-PT levels $(\geq 10 \mathrm{EU} / \mathrm{ml})$ at birth. Anti-pertussis antibody concentrations were extremely low in pregnant women in Turkey where childhood pertussis vaccination coverage has been high for a long time. Despite effective placental antibody transfer, umbilical cord pertussis antibody concentrations are similarly low. A majority of young infants are vulnerable to pertussis infection until the onset of primary vaccinations. These data support the need for pertussis vaccination during pregnancy to prevent infant infection in Turkey.

Key words: cord blood, pertussis, pertussis antibodies, pregnant women, seroprevalance.

Diphtheria-tetanus-pertussis (DTP3) immunization coverage is estimated at $86 \%$ worldwide, reaching more than $90 \%$ in the 129 (66\%) of 194 WHO member states ${ }^{1}$. However, despite this high vaccination coverage, pertussis continues to be a global public health problem. The WHO estimates that 16 million new cases of pertussis occur every year, with more than 63,000 pertussis deaths ${ }^{2}$. The majority of pertussis-related deaths occur in infants younger than 3 months old ${ }^{3,4}$. Therefore, any protection that can be provided at this age is crucial.
Protection against pertussis can best be achieved by active immunization, but the first dose of pertussis vaccine cannot be given before 6 weeks of age, because immune systems of newborn infants are not able to respond well to pertussis vaccine. Furthermore, pertussis vaccination does not offer immediate protection. It takes several days to respond to the vaccine. Even though partial protection against serious disease begins after the first dose of pertussis vaccine, full infant protection is not likely to be achieved until after the completion of primary vaccination at 6 months $s^{5,6}$. Therefore, 
in the first months of life, infants depend on maternal antibodies for protection until they develop immunity by vaccination ${ }^{7}$.

Maternal antibodies against $B$. pertussis antigens are transferred from mother to infant across the placenta and may protect infants from severe pertussis disease for a varying period of time, depending on the level of placental transmission and the rate of decay of passively acquired antibodies ${ }^{7}$. There is a highly significant correlation between the level of anti-PT IgG antibody in the serum and protection against pertussis $^{8-10}$. In the pre-vaccine era, $30-50 \%$ of pregnant women had circulating antibodies against pertussis ${ }^{11}$. However, in the post-vaccine era, studies carried out on women vaccinated in childhood showed low levels of pertussis antibodies in both mothers and newborns ${ }^{12-16}$.

In Turkey, routine childhood pertussis immunization with whole cell pertussis vaccine (DTP) was started in 1968 and was administered in the 2nd, 3rd and 4th months of life, with a booster dose in the 18th month. In 2007, acellular pertussis vaccine (DTaP) was introduced, and the third dose DTaP vaccination coverage reached $97 \%$ in 200917 . In 2010, a childhood booster vaccine of DTaP was added to the immunization schedule for 5-6 year old children in the first grade of elementary school. However, additional boosters for adolescents or adults have not been incorporated into the Turkish immunization schedule. Cocooning strategy and pertussis vaccination during pregnancy is not yet a current practice.
Pertussis serologic data for pregnant women and newborn infants in Turkey are lacking. There is only one previously published study investigating pertussis seroprevalence in cord and maternal blood ${ }^{15}$. Therefore, in this study, we aimed to determine the anti-pertussis antibody levels in paired maternal delivery and cord blood samples, to evaluate the placental transfer of these antibodies, and to assess whether newborn infants born in Turkey have adequate antibody levels against pertussis.

\section{Material and Methods}

\section{Study population}

The study was carried out in 251 motherinfant pairs admitted between April and June 2011. Participants eligible for enrollment were pregnant women aged 18-45 years old, who delivered a healthy term infant $\geq 37$ weeks' gestation and their term infants. Exclusion criteria for mother-infant pairs were serious underlying disease, multiple gestation or antenatal detection of a major birth defect in the infants. Infants born before 37 weeks of gestation were also excluded.

The study was approved by the Medical Ethical Committee (Meeting number 16/1 in 06.04.2011). The written informed consent was obtained from all mothers. The mothers were asked to complete a brief questionnaire collecting information on basic demographics, health, and pertussis immunization history. In addition, maternal age, gestational age, mode of delivery, gender of newborn and birth weight were recorded.

Table I. Demographic Characteristics of Mothers and Their Infants in the Study Population $(n=251)$.

\begin{tabular}{lc}
\hline Maternal age, mean \pm SD (range), years & $28.2 \pm 5.3(16-45)$ \\
Age groups of mothers, n (\%) & $10(4.0)$ \\
$<20$ years & $59(23.5)$ \\
$20-24$ years & $80(31.9)$ \\
$25-29$ years & $76(30.3)$ \\
$30-34$ years & $26(10.4)$ \\
$35-45$ years & $142(56.5)$ \\
Mode of delivery, n $\%)$ & $109(43.5)$ \\
Vaginal & $39.2 \pm 1.0(37-42)$ \\
Cesarean & $\pm 485.6(2200-5000)$ \\
Bestational age, mean \pm SD (range), weeks & $124(49.4)$ \\
Sex of neight, mean \pm SD (range), gram & $127(50.6)$ \\
Male & $3370.6 \pm 0.6$
\end{tabular}


Table II. Geometric Mean Concentrations of Anti-Pertussis Antibodies in Maternal Delivery Serum and Cord Blood Samples and Placental Transfer Ratios.

\begin{tabular}{lccc}
\hline & \multicolumn{2}{c}{ Geometric mean concentrations $(95 \% \mathrm{CI})$ [range], } & \\
\cline { 2 - 3 } & ELISA units/ml & & $\begin{array}{c}\text { Placental transfer ratio } \\
(\%)\end{array}$ \\
\cline { 2 - 3 } Anti-PT & 4.12 & Cord blood & \\
& $(3.53-4.80)$ & 5.49 & 133 \\
Anti-FHA & {$[0.10-151.36]$} & $(4.58-6.53)$ & \\
& 9.89 & {$[0.06-199.53]$} & 131 \\
\hline
\end{tabular}

CI: Confidence interval

\section{Laboratory Methods}

Blood samples were obtained from mothers immediately after delivery (maternal blood) and from the umbilical cord (cord blood). Paired maternal and umbilical cord blood samples were centrifuged and serum samples were stored at $-80^{\circ} \mathrm{C}$ until analyzed. Anti-PT IgG and anti-FHA IgG antibody ELISA tests were performed at Public Health Institution of Turkey, Microbiology Reference Laboratories, Vaccine Preventable Bacterial Diseases Serology Laboratory. The standardization of this in-house ELISA for pertussis serology was studied and published previously ${ }^{18}$. In brief, the test was conducted by using 96-well flat-bottom plates (Greiner, 655001, Frickenhausen, Germany). Purified PT $10 \mu \mathrm{g}$ PN/ampoule (JNIH-5, Biken, Japan) and Purified FHA $10 \mu \mathrm{g}$ PN/ampoule (JNIH-4, Biken, Japan) were used for coating the plates. The concentration of PT and FHA antigen in $100 \mu \mathrm{l}$ coating buffer was $0.1 \mu \mathrm{g}$ $\mathrm{PN} / \mathrm{ml}$ and $0.04 \mu \mathrm{g} \mathrm{PN} / \mathrm{ml}$, respectively. Coated plates were incubated at $4^{\circ} \mathrm{C}$ for 48 hours. The plates were blocked by adding $125 \mu \mathrm{l}$ of blocking buffer (PBS containing 0.5\% BSA) and incubated on an Incubator/shaker (Labsystem iEMS, Helsinki, Finland). Eight two-fold serial dilutions of test sera and reference serum (anti-Pertussis Reference human sera IgG [250 ELISA Unit (EU) for anti-PT IgG, 400 EU for anti-FHA IgG, Biken, Japan]) in PBS containing $0.5 \%$ BSA and $0.05 \%$ Tween 80 were added. Fc-specific alkaline phosphataseconjugated goat anti-human IgG (Seikagaku, Kogyou, Tokyo, Japan) diluted in PBS-T was then added; P-Nitrophenyl phosphate (Sigma) diluted in diethanolamine buffer $(1 \mathrm{mg} / \mathrm{ml}$, $\mathrm{pH}$ 9.6) was then added and $3 \mathrm{M} \mathrm{NaOH}$ was used as the stop solution. Plates were read at A405/630 on an ELISA reader (Labsystem, Multi Skan EX, Helsinki, Finland). The antiPT and anti-FHA IgG antibody titers were calculated by the parallel line assay $(\mathrm{p}=0.05)$.

Serum levels of anti-PT and anti-FHA antibodies were reported as enzyme-linked immunosorbent assay (ELISA) units per milliliter $(\mathrm{EU} / \mathrm{ml})$. The lower limit of detection for both antibodies by this method was 1.0 $\mathrm{EU} / \mathrm{ml}$. Although protective antibody levels against pertussis infection have not been clearly established, antibody levels $\geq 10 \mathrm{EU} / \mathrm{ml}$ were considered as a threshold for protection which is based on the lowest antibody levels among children recovering from pertussis ${ }^{19}$. In this study, antibody levels $\geq 10 \mathrm{EU} / \mathrm{ml}$ were also accepted as protected. Antibody levels $\geq 100$ $\mathrm{EU} / \mathrm{ml}$ for anti-PT antibody were considered as indicative of current or recent pertussis infection ${ }^{19,} 20$.

\section{Statistical Analysis}

Statistical analysis was performed with SPSS version 20.0 for Windows (SPSS, Chicago, IL). Anti-PT and anti-FHA antibody concentrations in serum samples were calculated as geometric mean concentrations (GMCs) with $95 \%$ confidence intervals $(95 \% \mathrm{CI})$. Placental transfer of pertussis antibodies was defined by calculating the ratio of antibody GMCs for umbilical cord and maternal serum. Mann -Whitney $U$ test was used for the comparison of means between the groups. A value of $\mathrm{p}<$ 0.05 was considered as statistically significant. Multivariate regression analysis was performed to determine the influence of variables (e.g. maternal age, gestational age, birth weight and 
gender of infants) on anti-pertussis antibody GMCs.

\section{Results}

A total of 251 mother-infant pairs were enrolled in the study. The mean maternal age was 28.2 years (range, 16-45 years). The mean gestational age was 39.2 weeks (range, 3742 weeks) and the mean birth weight was 3370 g (range, 2200-5000 g). Demographic characteristics of the study population are summarized in Table I. None of the mothers received Tdap during pregnancy and none of them reported prolonged cough (lasting $\geq 2$ weeks) or contact with a person suffering from prolonged cough during pregnancy.

Maternal and cord blood geometric mean concentrations (GMCs) for anti-PT and FHA antibodies are shown in Table II. Maternal GMCs of anti-PT and anti-FHA antibodies were 4.12 and $9.89 \mathrm{EU} / \mathrm{mL}$, respectively. In cord blood samples, GMCs of anti-PT and anti-FHA were $5.49 \mathrm{EU} / \mathrm{mL}$ and $12.73 \mathrm{EU} /$ $\mathrm{mL}$, respectively. The placental transfer ratios of pertussis antibodies were $133 \%$ for anti-PT and $131 \%$ for anti-FHA. In all maternal age groups, cords had higher titers than maternal serum samples and placental transfer ratios ranged between $127 \%-139 \%$ for anti-PT and $126 \%-134 \%$ for anti-FHA.

When levels of $\geq 10 \mathrm{EU} / \mathrm{ml}$ were accepted as protective concentrations, protective levels of anti-PT and anti-FHA were found in only $25.1 \%$ and $54.6 \%$ of maternal serum samples, respectively. The percentage of protective concentrations of anti-PT and anti-FHA in umbilical cord blood samples were $34.6 \%$ and $59.0 \%$, respectively (Table III).

Anti-PT levels $\geq 100 \mathrm{EU} / \mathrm{ml}$, which is the serologic evidence of recent pertussis infection, were detected in $3(1.2 \%)$ maternal serum samples. Infants of the 3 mothers with evidence of recent infection all had anti-PT levels of $\geq 100 \mathrm{EU} / \mathrm{ml}$.

Maternal anti-PT and anti-FHA levels were significantly correlated $(\mathrm{p}<0.001)$ with umbilical cord blood anti-PT and anti-FHA levels; $r=0.798$ and $r=0.886$, respectively. There was no association between maternal anti-PT or anti-FHA levels and maternal age. There was also no association between cord anti-PT or anti-FHA levels and either gestational age or birth weight.

\section{Discussion}

In recent studies investigating pertussis seroprevalence in paired maternal and cord blood samples, maternal GMCs of anti-PT and anti-FHA were reported to range between 2.4$11 \mathrm{EU} / \mathrm{ml}$ and 6.9-26.6 EU/ml, respectively and cord GMCs for anti-PT and anti-FHA were reported to range between 4.1-21.5 EU/ml and 12.3-32.0 EU/ml, respectively $12,13,16,21-23$. In our study, the GMCs of anti-PT and anti-FHA antibodies were 4.1 and $9.9 \mathrm{EU} / \mathrm{ml}$, respectively in maternal serum; and $5.5 \mathrm{EU} / \mathrm{ml}$ and 12.7 $\mathrm{EU} / \mathrm{ml}$, respectively in umbilical cord blood samples. Also, a recent study from Turkey observed similar low anti-pertussis antibody levels in cord and maternal blood ${ }^{15}$. These data suggest that even in countries where pertussis vaccine coverage for children has been high for a long time, like Turkey, anti-pertussis antibody concentrations were extremely low in pregnant women and their newborn infants.

The present study suggests that there is a strong correlation between maternal and cord anti-pertussis antibody levels. Recent studies observed higher anti-pertussis antibody levels in cord blood samples than in maternal blood samples ${ }^{13,15,16,23,24}$. We also observed higher anti-PT and anti-FHA antibody levels

Table III. The Percentage of Protective Levels of Anti-PT and Anti-FHA ( $\geq 10 \mathrm{EU} / \mathrm{ml})$ in Maternal and Cord Blood Samples and the Percentage of Recent Maternal Pertussis Infection (Anti PT $\geq 100$ EU/ml) $(n=251)$.

\begin{tabular}{|c|c|c|c|}
\hline \multirow[b]{2}{*}{ Variable } & \multicolumn{2}{|c|}{ Percentage of protective antibody levels } & \multirow{2}{*}{$\begin{array}{l}\text { Recent pertussis infection } \\
\text { Anti-PT } \geq 100 \mathrm{EU} / \mathrm{mL}\end{array}$} \\
\hline & Anti-PT $\geq 10 \mathrm{EU} / \mathrm{ml}$ & Anti-FHA $\geq 10 \mathrm{EU} / \mathrm{ml}$ & \\
\hline Maternal serum, $\mathrm{n}(\%)$ & $63(25.1)$ & $137(54.6)$ & $3(1.2)$ \\
\hline Cord blood, $\mathrm{n}(\%)$ & $87(34.6)$ & $148(59)$ & $3(1.2)$ \\
\hline
\end{tabular}


in umbilical cord blood than in maternal blood. Placental transfer to the infants in our study of pertussis antibodies was $133 \%$ for anti-PT and $131 \%$ for anti-FHA. Moreover, infants born to mothers who had serologic evidence of recent pertussis infection all had anti-PT antibody levels higher than 100 $\mathrm{EU} / \mathrm{ml}$. The efficiency of placental transfer demonstrates the potential for neonatal and infant protection against pertussis when levels of maternal pertussis-specific antibody are elevated $^{13}$. However, despite efficient placental transfer, cord pertussis antibody levels were found to be too low. Only $34.6 \%$ of newborn infants have been protected against pertussis infection, according to the arbitrary cut-off value associated with potential protection. A majority of these infants are vulnerable to pertussis disease because levels of passively acquired maternal antibody are too low to provide any significant degree of protection.

The potential for protection of the infants exists by the provision, during pregnancy, of higher levels of pertussis antibodies ${ }^{13}$. Recent studies have also suggested that pertussis vaccination during pregnancy directly protects young infants through the transfer of maternal pertussis antibodies, in addition to being effective, safe, and well tolerated ${ }^{25-31}$. Maternal vaccination with the tetanus, diphtheria, and acellular pertussis (Tdap) during pregnancy has recently been recommended in several countries such as the United States, Argentina, Belgium, Israel, New Zealand, and the United Kingdom ${ }^{4,32}$. In Turkey, maternal vaccination with a tetanus toxoid (TT) was started in 1994. In 2004, the tetanus-diphtheria (Td) vaccine replaced the TT vaccine in the maternal immunization schedule and $\mathrm{Td}$ vaccine coverage among pregnant women reached $62 \%$ in 2012. However, pertussis vaccination during pregnancy is not a current practice in Turkey.

The present study shows that most pregnant women in Turkey have low levels of anti-pertussis antibody. Despite effective maternal antibody transfer, pertussis antibody concentrations are too low in newborn infants to provide adequate protection against pertussis infection. A majority of newborn infants are vulnerable to pertussis infection. These data support the need for pertussis vaccination during pregnancy for preventing infant infection in Turkey. It might be a practical approach to replace the Td vaccine with Tdap vaccine in the routine maternal immunization schedule of Turkey.

\section{Acknowledgements}

We thank the nurses and doctors of the Department of Obstetric and Gynaecology at Izmir Tepecik Training and Research Hospital.

\section{REFERENCES}

1. Subaiya S, Dumolard L, Lydon P, Gacic-Dobo M, Eggers $\mathrm{R}$, Conklin L. Global Routine Vaccination Coverage, 2014. MMWR Morb Mortal Wkly Rep 2015; 64: 1252 1255.

2. Pertussis vaccines: WHO position paper, August 2015 . Wkly. Epidemiol Rec 2015; 90: 433-460.

3. Vitek CR, Pascual FB, Baughman AL, Murphy TV. Increase in deaths from pertussis among young infants in the United States in the 1990s. Pediatr Infect Dis J 2003; 22: 628-634.

4. Forsyth $\mathrm{K}$, Plotkin S, Tan T, Wirsing von König $\mathrm{CH}$. Strategies to decrease pertussis transmission to infants. Pediatrics 2015; 135: 1475-1482.

5. Juretzko P, von Kries R, Hermann M, Wirsing von König CH, Weil J, Giani G. Effectiveness of acellular pertussis vaccine assessed by hospital-based active surveillance in Germany. Clin Infect Dis 2002; 35: 162-167.

6. Quinn HE, Snelling TL, Macartney KK, McIntyre PB. Duration of protection after first dose of acellular pertussis vaccine in infants. Pediatrics 2014; 133: e513-e519.

7. Van Rie A, Wendelboe AM, Englund JA. Role of maternal antibodies in infants. Pediatr Infect Dis J 2005; 24 (5 Suppl): 62-65.

8. Cherry JD, Gornbein J, Heininger U, Stehr K. A search for serologic correlates of immunity to Bordetella pertussis cough illnesses. Vaccine 1998; 16: 1901-1906.

9. Storsaeter J, Hallander HO, Gustafsson L, Olin P. Levels of anti-pertussis antibodies related to protection after household exposure to Bordetella pertussis. Vaccine 1998; 16: 1907-1916.

10. Taranger J, Trollfors B, Lagergard T, et al. Correlation between pertussis toxin IgG antibodies in postvaccination sera and subsequent protection against pertussis. J Infect Dis 2000; 181:1010-1013.

11. Miller JJ, Harold KF, Ryan ML, Silverberg RJ, Lew E. Immunization against pertussis during the first four months of life. Pediatrics 1949; 4: 468-478.

12. Bigham M, Konrad S, Van Buynder P, et al. Low pertussis toxin antibody levels in two regional cohorts of Canadian pregnant women. Vaccine 2014; 32: 6493 6498.

13. Healy CM, Munoz FM, Rench MA, Halasa NB, Edwards $\mathrm{KM}$, Baker CJ. Prevalence of pertussis antibodies in maternal delivery, cord, and infant serum. J Infect Dis 2004; 190: 335-340.

14. Fallo A, Manonelles G, Hozbor D, et al. Pertussis 
seroprevalence in adults, post-partum women and umbilical cord blood. Arch Argent Pediatr 2014; 112: 315-322.

15. Ercan TE, Sonmez C, Vural M, Erginoz E, Torunoğlu MA, Perk Y. Seroprevalance of pertussis antibodies in maternal and cord blood of preterm and term infants. Vaccine 2013; 31: 4172-4176.

16. Gonik B, Puder KS, Gonik N, Kruger M. Seroprevalence of Bordetella pertussis antibodies in mothers and their newborn infants. Infect Dis Obstet Gynecol 2005; 13: 59-61.

17. Kurugöl Z. Boğmaca aşısı ve sorunlar. ANKEM Dergisi 2011; 25: 212-217.

18. Çöplü N, Esen B, Kurtoğlu D, Gözalan A, Miyamura K, Yoshida I. Standardization of an in-house ELISA for pertussis serology and its application in a seroepidemiological study. Mikrobiyol Bul 2005; 39: 281-289.

19. Giammanco A, Chiarini A, Maple PA, et al. European Sero-Epidemiology Network: standardization of the assay results for pertussis. Vaccine 2003; 22: 112-120.

20. Baughman AL, Bisgard KM, Edwards KM, et al. Establishment of diagnostic cutoff points for levels of serum antibodies to pertussis toxin, filamentous hemagglutinin, and fimbriae in adolescents and adults in the United States. Clin Diagn Lab Immunol 2004; 11: 1045-1053.

21. Plans P, Jansà J, Doshi N, Harrison TG, Plasència A. Prevalence of pertussis antibodies in umbilical cord blood samples in Catalonia, Spain. Pediatr Infect Dis J 2008; 27: 1023-1025.

22. Heininger U, Riffelmann M, Leineweber B, Wirsing von Koenig $\mathrm{CH}$. Maternally derived antibodies against Bordetella pertussis antigens pertussis toxin and filamentous hemagglutinin in preterm and full term newborns. Pediatr Infect Dis J 2009; 28: 443-445.

23. de Voer RM, van der Klis FR, Nooitgedagt JE, et al. Seroprevalence and placental pransportation of maternal antibodies specific for Neisseria meningitidis serogroup C, Haemophilus influenzae type B, diphtheria, tetanus, and pertussis. Clin Infect Dis 2009; 49: 58-64.
24. Shakib JH, Ralston S, Raissy HH, Stoddard GJ, Edwards $\mathrm{KM}$, Byington CL. Pertussis antibodies in postpartum women and their newborns. J Perinatol 2010; 30: 9397.

25. Gall SA, Myers J, Pichichero M. Maternal immunization with tetanus-diphtheria-pertussis vaccine: effect on maternal and neonatal serum antibody levels. Am J Obstet Gynecol 2011; 204: e1-e5.

26. Leuridan E, Hens N, Peeters N, de Witte L, Van der Meeren O, Van Damme P. Effect of a prepregnancy pertussis booster dose on maternal antibody titers in young infants. Pediatr Infect Dis J 2011; 30: 608-610.

27. Vilajeliu A, Goncé A, López M, et al; PERTU Working Group. Combined tetanus-diphtheria and pertussis vaccine during pregnancy: transfer of maternal pertussis antibodies to the newborn. Vaccine 2015; 33: 10561062.

28. Munoz FM, Bond NH, Maccato M, et al. Safety and immunogenicity of tetanus diphtheria and acellular pertussis (Tdap) immunization during pregnancy in mothers and infants: A randomized clinical trial. JAMA 2014; 311:1760-1769.

29. Walls T, Graham P, Petousis-Harris H, Hill L, Austin $\mathrm{N}$. Infant outcomes after exposure to Tdap vaccine in pregnancy: An observational study. BMJ Open 2016; 6: e009536.

30. Donegan K, King B, Bryan P. Safety of pertussis vaccination in pregnant women in UK: observational study. BMJ 2014; 349: g4219.

31. Amirthalingam G, Andrews N, Campbell $\mathrm{H}$, et al Effectiveness of maternal pertussis vaccination in England: an observational study. Lancet 2014; 384: 1521-1528.

32. Centers for Disease Control Prevention. Updated recommendations for use of tetanus toxoid, reduced diphtheria toxoid and acellular pertussis vaccine(Tdap) in pregnant women-Advisory Committee on Immunization Practices(ACIP), 2012. MMWR Morb Mortal Wkly Rep 2013; 62: 131-135. 